\title{
A STUDY ON STRUCTURAL ANALYSIS OF ELECTROPLATED NANO CRYSTALLINE NICKEL BASED THIN FILMS
}

\author{
R. Kannan ${ }^{1}$, M. Selvambikai ${ }^{1 *}$, I. Jeena Rajathy ${ }^{2}$ and S. Ananthi ${ }^{3}$ \\ 1,*Department of Physics, Kumaraguru College of Technology, \\ Coimbatore-641 049, T.N., India. \\ ${ }^{2}$ Department of Physics, Sasurie College of Engineering, \\ Vijayamangalam -638 056, T.N.India. \\ ${ }^{3}$ Department of Physics, Nandha College of Technology, Erode-638 052, T.N., India. \\ *E-mail: selvambikai.m.sci@kct.ac.in
}

\begin{abstract}
The present work focuses on the synthesis and structural characterization of nickel based thin films like NiFeAg, NiMo, NiMoW and NiFeP through electrodeposition method. All these nickel based thin films were successfully coated on the copper substrate at a constant current density of $10 \mathrm{~A} / \mathrm{dm}^{2}$ and 30 minutes time of deposition. The chemical composition of the synthesized thin films was analyzed by using Energy Dispersive X-ray Analysis (EDAX) spectrograph. The surface morphology of the electroplated films was investigated by using Scanning Electron Microscope (SEM).The X-ray diffraction pattern of coated thin films reveals the crystalline nature, structure, and size. The nickel based thin films already have numerous industrial applications which include Micro Electro Mechanical system (MEMS). The main aim of this current research work is to develop the new permalloy $\left(\mathrm{Ni}_{80 \%} \mathrm{Fe}_{20 \%}\right)$ based thin films for fabrication of MEMS devices.
\end{abstract}

Keywords: Synthesis, electrodeposition, NiFeAg, thin films, crystalline, and MEMS.

(C) RASĀYAN. All rights reserved

\section{INTRODUCTION}

The most common suitable method for the nickel based nano crystalline magnetic thin films is electrodeposition process due its advantages like low cost, high efficiency etc., One of the well-known Ni-based alloy thin films for MEMS application is NiFe which is called permalloy $\left(\mathrm{Ni}_{80 \%} \mathrm{Fe}_{20 \%}\right)$ due to its excellent magnetic behaviours like low coercivity, high saturation magnetization, and better corrosion resistance $^{1}$. Still, there is a major problem to control the corrosion behavior of NiFe alloy thin films ${ }^{2}$. In order to control the corrosion and enhance the magnetic nature, the third element was decided to add with $\mathrm{NiFe}$ alloys like $\mathrm{P}^{3}, \mathrm{Mo}^{4}, \mathrm{Ag}^{5}, \mathrm{~W}^{6}, \mathrm{Cr}^{7}$ etc., The addition of $\mathrm{W}$ to the $\mathrm{NiFe}$ alloy thin films showed the enhanced corrosion behaviour with better magnetic properties are reported by Kannan et al., The present investigation mainly concentrates the surface analysis of nickel based thin films synthesised from electrodeposition method to exploit its full potential which may be used for the fabrication of MEMS devices.

\section{EXPERIMENTAL}

The NiFeAg, NiMo, NiMoW and NiFe P thin films were electroplated on the copper substrate by using relevant chemicals in di-ammonium citrate bath. In order to prepare the electroplating bath, all the reagent grade chemicals were dissolved in triple distilled water and the corresponding $\mathrm{pH}$ value was adjusted to 8 by adding few drops of ammonia solution. Separate baths have been prepared for each nickel based thin films like $\mathrm{NiFeAg}$, NiMo, NiMoW, and NiFeP. The chemical composition and optimized bath condition of NiFeP thin films are shown in Table-1 and remaining baths were also optimized. A copper plate of size $1.5 \times 7 \mathrm{~cm}$ was used as a cathode and pure stainless steel of the same size as an anode.Initially, all the substrates were degreased by using soap solution followed by $5 \%$ sulphuric acid and finally rinsed with 
triple distilled water just before the deposition. An adhesive tape was used to mask off all the surface of copper plate except the desired area for nickel based thin film deposition. The nickel based thin films were electroplated by applying a constant current of $75 \mathrm{~mA}$ for the period of 30 minutes at a bath temperature of $30^{\circ} \mathrm{C}$.

In order to explore the surface analysis of nickel based thin films, all the coated nickel based thin films were subjected to the various characterization techniques like EDAX, SEM, and XRD. The crystalline size was calculated using the Scherrer's formula, ${ }^{8,9}$

$$
D=\frac{0.945 \lambda}{\beta \operatorname{Cos} \theta}
$$

The strain $(\varepsilon)$ was calculated from the relation:

$$
\varepsilon=\frac{\beta \cos \theta}{4}
$$

The dislocation density $(\delta)$ was found from the relation:

$$
\delta=\frac{1}{\mathrm{D}^{2}}
$$

Table-1: Electrodeposition bath for NiFeP thin films

\begin{tabular}{c|l|c}
\hline S. No. & Name of the chemical parameters & $\begin{array}{c}\text { Data } \\
\mathrm{g} / 1\end{array}$ \\
\hline 1. & Nickel sulphate & 70 \\
\hline 2. & Ferrous sulphate & 35 \\
\hline 3. & Phosphorus acid & 15 \\
\hline 4. & Thiourea & 7.5 \\
\hline 5. & Diammonium citrate & 75 \\
\hline 6. & Citric acid & 5 \\
\hline 7. & Boric acid & 15 \\
\hline 8. & pH value & 8 \\
\hline 9. & Temperature & $30^{\circ} \mathrm{C}$ \\
\hline 10. & Current density & $10 \mathrm{~A} / \mathrm{dm}^{2}$ \\
\hline
\end{tabular}

\section{RESULTS AND DISCUSSION}

The chemical analysis of the NiFeAg, NiMo, NiMoW and NiFeP thin films from EDAX data shown in Fig.-1. All the electroplated thin films have strong adherent to the substrate and they were uniform, smooth and crack free. The weight percentage of the films is shown in Table- 2 .

The EDAX data clearly shows that the maximum $\mathrm{Ni}$ content of $85.19 \%$ was present in the $\mathrm{NiFeP}$ electroplated thin films along with $10.86 \%$ of Fe content. But in the NiFeAg thin film alloys have the lowest nickel content with highest Fe content. The moderate level of Ni content was present in the NiMoW alloy thin films. Because of the lowest Fe content with $15 \%$ of phosphorus, the NiFeP thin films may use for the MEMS applications due to its improved magnetic nature and corrosion resistant.

Table-2: Weight percentage of nickel based thin films

\begin{tabular}{c|c|c|c|c|c|c|c|c}
\hline S. No. & $\begin{array}{c}\text { Name of the } \\
\text { nickel based } \\
\text { thin films }\end{array}$ & $\begin{array}{c}\text { Bath temperature } \\
{ }^{\circ} \mathrm{C}\end{array}$ & $\begin{array}{c}\mathrm{Ni} \\
\mathrm{Wt} \%\end{array}$ & $\begin{array}{c}\mathrm{Mo} \\
\mathrm{Wt} \%\end{array}$ & $\begin{array}{c}\mathrm{Fe} \\
\mathrm{Wt} \%\end{array}$ & $\begin{array}{c}\mathrm{W} \\
\mathrm{Wt} \%\end{array}$ & $\begin{array}{c}\mathrm{P} \\
\mathrm{Wt} \%\end{array}$ & $\begin{array}{c}\mathrm{P} \\
\mathrm{Wt} \%\end{array}$ \\
\hline 1 & NiMo & 30 & 68.51 & 31.49 & - & - & - & - \\
\hline
\end{tabular}


RASĀYAN J. Chem.

Vol. 10 | No. 4 |1213-1217 | October - December | 2017

\begin{tabular}{l|c|c|c|c|c|c|c|c}
\hline 2 & NiMoW & 30 & 67.39 & 31.13 & & 1.48 & - & - \\
\hline 3 & NiFeAg & 30 & 4.11 & - & 80.21 & - & - & 15.68 \\
\hline 4 & NiFeP & 30 & 85.19 & - & 10.86 & - & 3.95 & \\
\hline
\end{tabular}
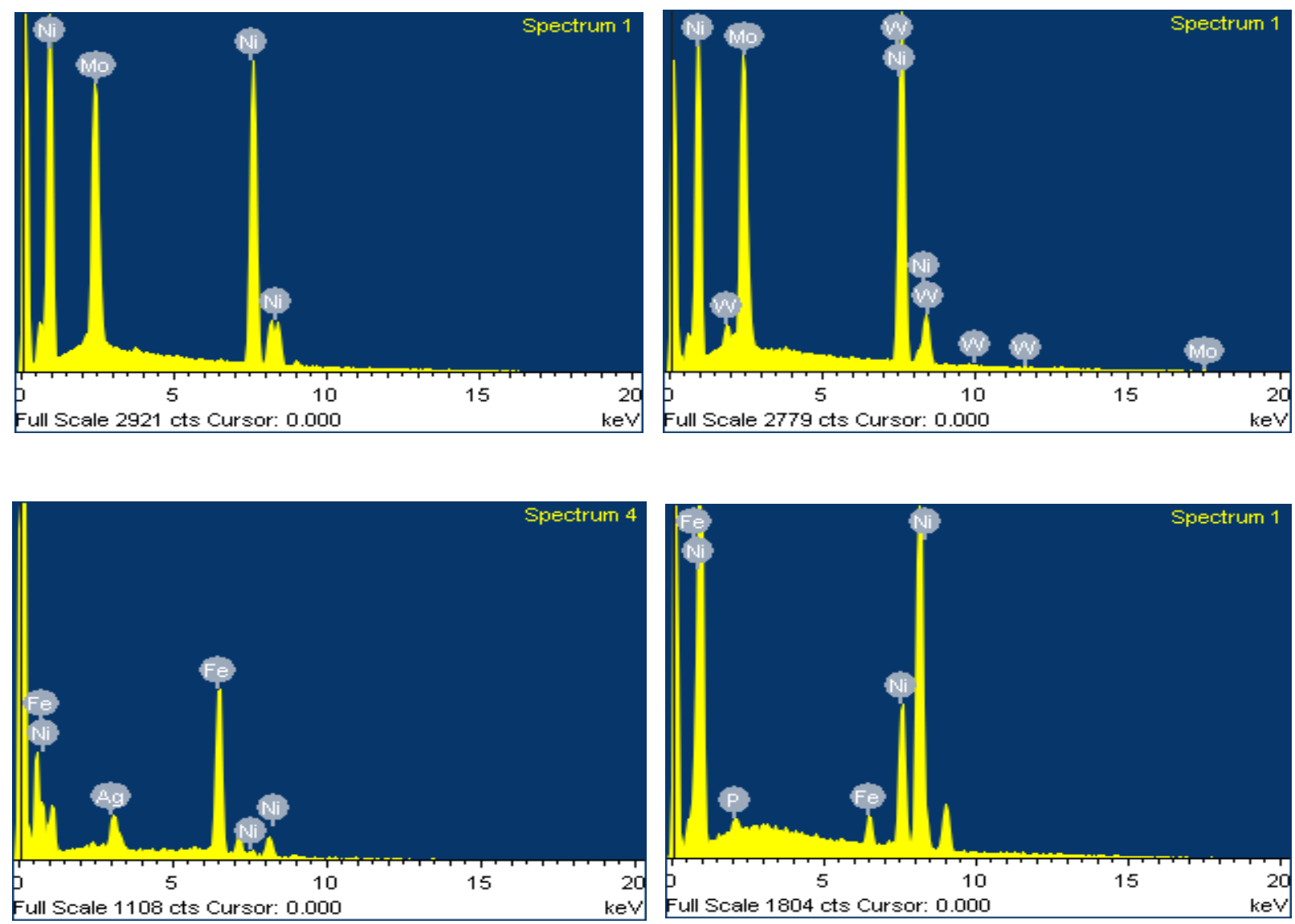

Fig.-1: EDAX spectrum of NiMo, NiMoW, NiFeAg and NiFeP thin films

\section{Surface Analysis of nickel based thin films}

The SEM images of NiMo, NiMoW, NiFeAg and NiFeP thin films are shown in Fig.-2.

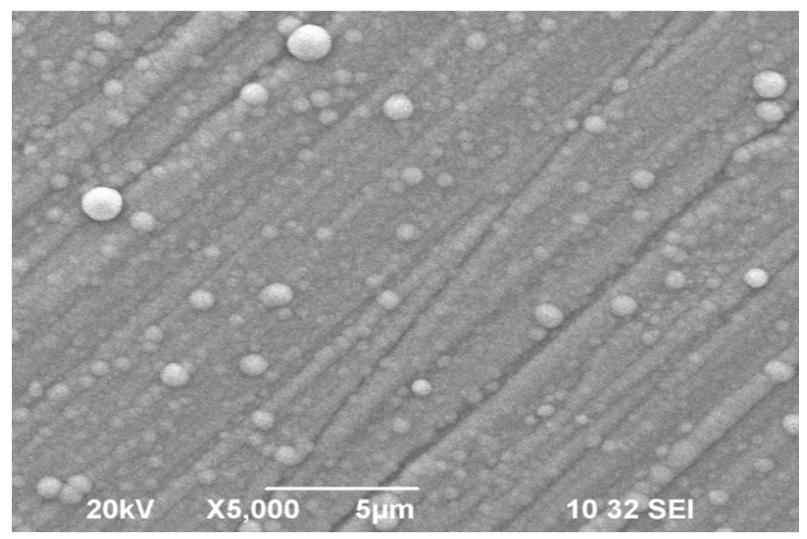

(a)

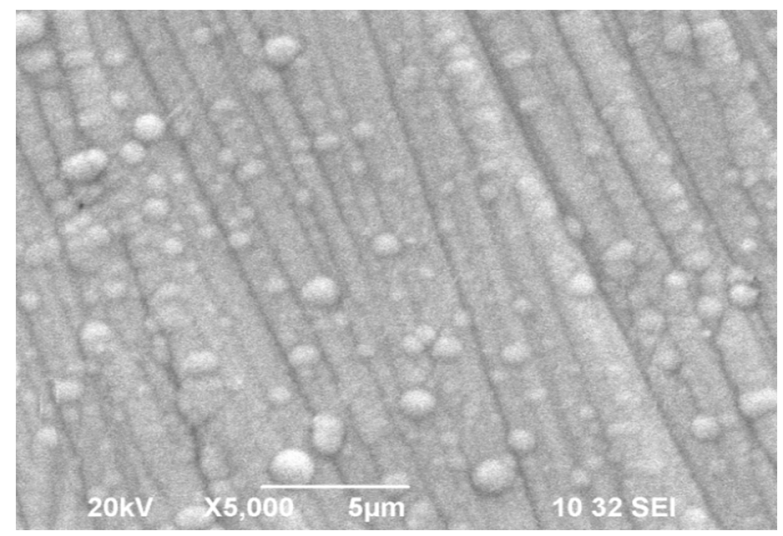

(b) 


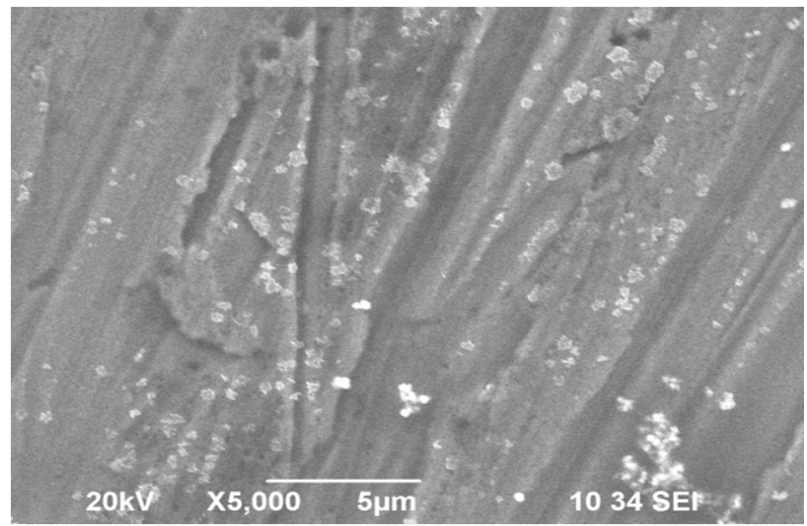

(c)

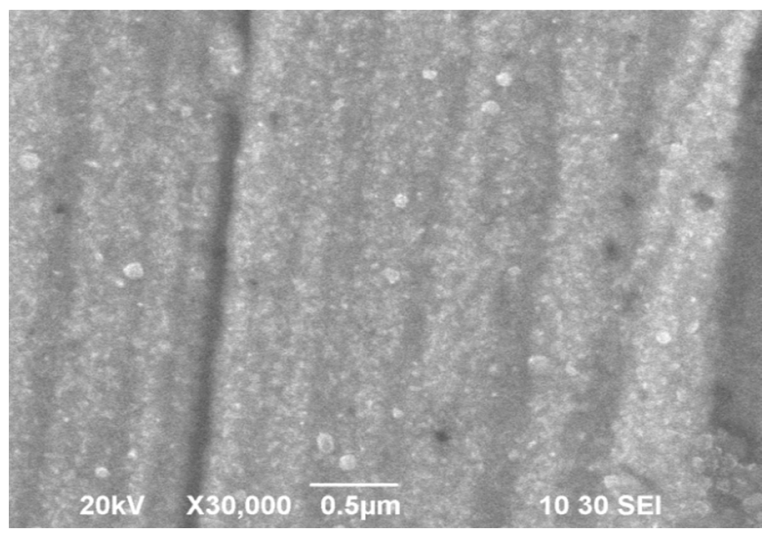

(d)

Fig.-2: SEM images of e thin films (a) NiMo (b) NiMoW (c) NiFeAg (d) NiFeP

There is no significant microvoid and micro-cracks in all the coated films. The crystal boundaries and crystal grains are clearly seen in the NiMo, NiMoW, NiFeAg and NiFeP thin films. The thickness of coated thin films is found to have few micrometers ( NiMo $-4.2 \mu \mathrm{m}$, NiMoW $-4.6 \mu \mathrm{m}, \mathrm{NiFe} \mathrm{Ag}-6.3$ $\mu \mathrm{m}$ and $\mathrm{NiFeP}-3.7 \mu \mathrm{m})$.

\section{X-ray analysis of nickel based thin films}

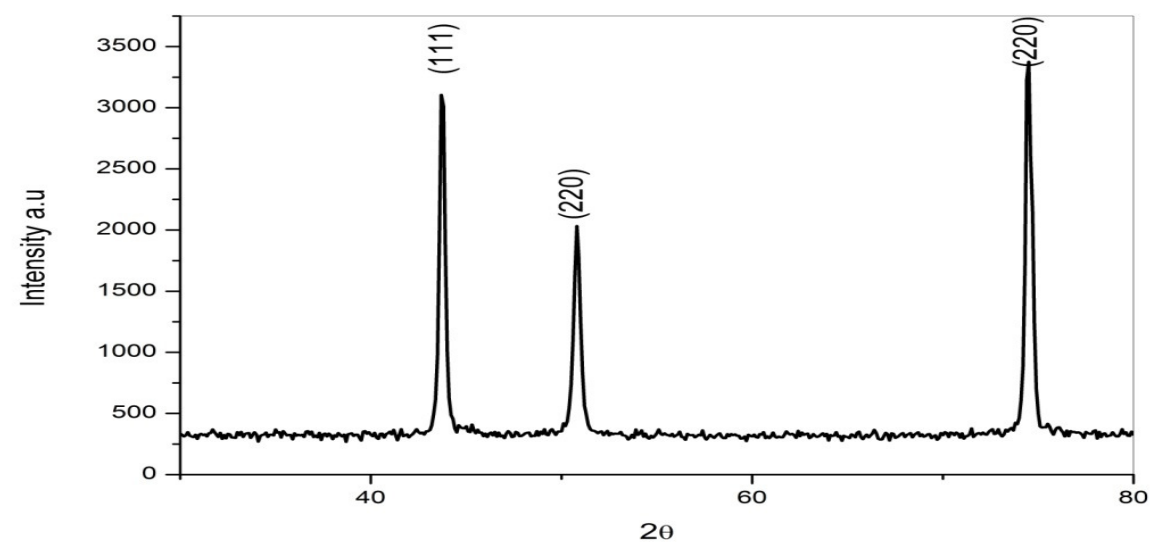

Fig.-3: X-ray analysis of NiFeAg thin films

Electrodeposited NiFeAg films from diammonium citrate bath were subjected to XRD studies and were studied for their structural characteristics as shown in Fig.-3. The presence of sharp peaks in XRD pattern reveals that the $\mathrm{NiFeAg}$ film is in crystalline nature. Crystalline size of the deposits was calculated from the XRD pattern using the Scherrer's formula.

Table-3: Crystalline size of NiFeAg thin films

\begin{tabular}{c|c|c|c|c|c}
\hline $\begin{array}{c}\text { Two theta } \\
(\text { degree })\end{array}$ & $\mathrm{d}(\AA)$ & $\begin{array}{c}\text { Full width half } \\
\text { maximum } \\
(\text { degree })\end{array}$ & $\begin{array}{c}\text { Crystalline size } \\
(\mathrm{nm})\end{array}$ & Strain $\left(10^{-3)}\right.$ & $\begin{array}{c}\text { Dislocation } \\
\text { density } \\
\left(10^{15}\right)\end{array}$ \\
\hline 44.2 & 2.0475 & 0.3150 & 28.84 & 1.262 & 1.2 \\
\hline 50.7 & 1.7966 & 03927 & 23.52 & 1.55 & 1.8 \\
\hline 74.4 & 1.273 & 0.3382 & 30.98 & 1.174 & 1.04 \\
\hline
\end{tabular}


The XRD pattern clearly shows that the crystalline size of electroplated NiFeAg thin films are on the nanoscale and the average crystalline size was around $27.78 \mathrm{~nm}$. The crystal size of NiFeAg alloy films obtained from diammonium citrate bath at $30^{\circ} \mathrm{C}$ is shown in Table 3 . The crystal structure of the coated thin films is found to have FCC with (111), (200) and (220) diffraction peaks.

\section{CONCLUSION}

The nickel based thin films were successfully coated on the copper substrate by applying the constant current of $75 \mathrm{~mA}$ for the period of 30 minutes at electroplate bath temperature of $30^{\circ} \mathrm{C}$. The EDAX analysis reveals the chemical composition of the synthesised thin films and the highest Ni content was observed for NiFeP alloy films with lowest Fe content. All the nickel based coated thin films were uniform, smooth, crack-free and strong adherent to the substrate. The thickness of the nickel based thin films is found to be in few micro meters. The XRD pattern clearly shows the crystalline nature of the coated thin films and the crystalline size of NiFeAg thin film was calculated as $27.78 \mathrm{~nm}$. Based on the magnetic properties, these electro-deposited nickel based thin films may utilize for the MEMS applications.

\section{REFERENCES}

1. R. Kannan, S. Ganesan, and T. M. Selvakumari, J. Optoelectron Adv.Mat., 14 (9-10), 774, (2012).

2. P. Esther, C. JosephKennady, P. Saravanan, and T. Venkatachalam, J. Non Oxide Glas., 1(3), 301(2009).

3. O.M. Hemeda , A. Tawfik , Adly H. El-Sayed and M.A. Hamad , J. Supercond. Nov. Magn., 28 (12), 3629 (2015).

4. Pao - Chang Huang, Kung- Hsu Hou, Gao-Liang Wang, Mao-Lin Chen and Jee-Ray Wang, Int. J. Electrochem. Sci.,10, 4972 (2015).

5. Hyeonjin Eom, Byungjun Jeon, Donguk Kim and Bongyoung Yoo, Mat. Trans.,51(10), 1842 (2010).

6. Y. D. Yu, G. Y. Wei, H. F. Guo, J. W. Lou and H. L. Ge, Surf. Eng., 28(1),30 (2012).

7. L Elias, KU Bhat and AC Hegde, RSC Advances., 6 (40), 34005(2016).

8. R. Kannan, S. Ganesan, and T. M. Selvakumari, Dig. J. Nanomater. Bios., 7 (3), 1039 (2012).

9. R.S.Futane, V. M. Raut and S.D.Dhande, Rasayan J.Chem.,9(4), 842 (2016).

[RJC-1925/2017] 